\title{
CRESCIMENTO ECONÔMICO E COMÉRCIO EXTERIOR: TEORIA E EVIDÊNCIAS PARA ALGUMAS ECONOMIAS ASIÁTICAS*
}

\author{
Marçal Serafim Cândido ${ }^{* *}$
}

Fabiano Guasti Lima ${ }^{* * *}$

\begin{abstract}
RESUMO A relação entre comércio exterior e crescimento econômico tem sido tema de longos debates na literatura econômica. A principal controvérsia desse debate se dá quanto a verdadeira contribuição do comércio no crescimento econômico e sua separação de outros efeitos que podem exercer influência tanto no comércio exterior quanto no crescimento econômico e a separação desses efeitos não são de forma alguma triviais. Neste trabalho, por meio da análise em painel, mostra-se que, mesmo com diversas técnicas de estimação por painel, o comércio exterior exerce influência positiva e significativa no crescimento econômico.
\end{abstract}

Palavras-chave: comércio internacional; crescimento econômico; países asiáticos Código JEL: O53; F10

\section{ECONOMIC GROWTH AND EXTERNAL TRADE: THEORY AND EVIDENCES FOR SOME ASIAN ECONOMIES}

ABSTRACT The relationship between trade and economic growth has been the subject of lengthy discussions in the economic literature. The main goal of this work is about the real contribution of trade in the economic growth and its separation

* Artigo enviado em 2 de fevereiro de 2009 e aprovado em 4 de março de 2010.

** Graduado em Economia e Contabilidade e mestrando pela Faculdade de Economia, Administração e Contabilidade de Ribeirão Preto da Universidade de São Paulo - FEA-RP/USP. Bolsista FAPESP (Fundação de Amparo à Pesquisa do Estado de São Paulo), e-mail: marcaldeserrana@yahoo. com.br

*** Professor doutor da Faculdade de Economia, Administração e Contabilidade de Ribeirão Preto da Universidade de São Paulo - FEA-RP/USP, e-mail: fabiano@francanet.com.br 
from other effects that can exert influence in both in foreign trade and economic growth, the separation of these effects is not trivial. This paper, through panel analysis shows that, even with several techniques pet trade panel outside influence positive and significant economic growth.

Key words: international trade; economic growth; asian countries 


\section{INTRODUÇÃO}

Os países do Leste Asiático apresentaram nas últimas décadas crescimento econômico superior à média dos países em desenvolvimento, com especial destaque para os países integrantes do chamado grupo dos "Tigres Asiáticos" (Coreia do Sul, Taiwan, Cingapura e Hong Kong), que receberam tal denominação pelo dinamismo alcançado por suas economias, bem como por suas práticas de comércio internacional agressivas, com produtos de alta competitividade e de expressiva ampliação na participação do comércio mundial.

Além desses países, dois outros vêm se mostrando como importantes polos de crescimento econômico acelerado: China e Índia. O primeiro vem empreendendo uma clara política de promoção de crescimento com forte apelo ao setor externo, e o segundo tem se mostrado no mesmo sentido, apesar de ser em época mais tardia e não com o aprofundamento mostrado pelas políticas comerciais chinesas.

Contudo, apesar de esses países terem logrado rápido crescimento do produto, acompanhado pelo aumento da abertura comercial e expansão do seu comércio exterior, não se pode afirmar que o comércio exterior foi a causa principal desse crescimento econômico observado, como bem lembrado por Krugman e Obstfeld (2004). Dessa maneira, outros fatores, mesmo que não diretamente observáveis, devem ser considerados quando da tentativa de uma explicação bem-fundamentada do êxito desses países na promoção do crescimento econômico.

A partir dessa necessidade de mostrar o papel desempenhado pelo comércio exterior desses países no crescimento do produto, aqui representado pelas taxas de crescimento do PIB, considerando as características peculiares de cada país, como o ambiente institucional, regulatório e de inovação, optou-se por utilizar a metodologia painel, a fim de obter estimativas consistentes da relação comércio exterior e crescimento econômico que não estejam influenciadas por fatores idiossincráticos dos países. Assim, foi aplicada tal metodologia para verificar essa relação crescimento econômico e comércio exterior para os seguintes países: Coreia do Sul, Filipinas, Malásia, Indonésia, Taiwan, China, Hong Kong e Índia. 
O desenvolvimento do trabalho dá-se da seguinte maneira: na próxima seção são discutidas algumas abordagens da relação comércio exterior e crescimento econômico de forma sucinta. Em seguida, na seção 2, são definidas as variáveis utilizadas e as justificativas de inclusão destas. Já na seção 3, mostra-se por que a metodologia de análise de dados em painel permite uma melhor estimativa da variável objetivo. Na seção 4, são apresentadas algumas estatísticas descritivas, estimativas obtidas, bem como as análises dos resultados. Por fim, são apresentadas as conclusões.

\section{A RELAÇÃO ENTRE COMÉRCIO INTERNACIONAL E CRESCIMENTO ECONÔMICO}

A relação entre comércio exterior e crescimento econômico é algo que ainda levanta muitos debates nos estudiosos do assunto. Tais debates surgem principalmente da dificuldade em separar os efeitos das políticas comerciais de promoção do comércio exterior de outros tipos de políticas paralelamente adotadas pelos países que as praticam. Krueger (1990, p. 109) aponta essa dificuldade:

One of the reasons it is difficult to identify the links between export growth and overall growth is that other policies adopted in the superexporting countries have also been conductive to growth.

A argumentação que baliza a afirmação de que o comércio exterior é um fato de grande influência do crescimento econômico está ligada à capacidade do comércio internacional de aumentar a utilização da capacidade produtiva, o que induz ao aumento dos níveis de investimento; melhora a alocação de recursos de acordo com as vantagens comparativas ${ }^{1}$ de cada país; aproveita os ganhos de escala, já que amplia o mercado para os produtos do país que se lança no comércio internacional; produz melhorias tecnológicas, pois a competitividade passa a ser atributo básico para concorrer no comércio exterior, além das melhorias da capacidade de gerenciamento para responder às pressões competitivas externas (Fukuda e Toya, 1993).

Tal afirmação encontra embasamento, também, em trabalhos como o de Krueger (1997), Greenaway, Morgan e Wright (2001) e Ventura (2005). Esses autores, por meio de análises estatísticas de diversos países, concluem que o comércio exterior é um dos meios mais importantes pelos quais se 
propaga o crescimento econômico; todavia, a liberalização deve ser acompanhada por outras políticas econômicas para que se possa obter êxito nas estratégias de desenvolvimento (Krueger, 1997). Há, ainda, estudos econométricos (Lee, Ricci e Rigobon, 2004) que demonstram os efeitos positivos do comércio exterior (e a integração econômica) no crescimento econômico. Tais autores, contudo, detêm-se no nível agregado, mas há também estudos no nível microeconômico (Kraay, 1997), que chegam a conclusão semelhante, ou seja, o comércio exterior atua positivamente no desempenho econômico. Outros trabalhos (Byrge e Pakko, 2006), de cunho mais exploratório, mostram a relação entre políticas comerciais de abertura externa, e concluem que países que adotaram políticas comerciais "livres", ou seja, de forte orientação à liberalização comercial, apresentaram taxas de crescimento econômico cerca de 0,7 pontos percentuais maiores que a de países que restringiram sua inserção externa.

Em estudo sobre os países asiáticos, Frankel, Romer e Cyrus (1996), com estimação de modelos de crescimento para alguns desses países, concluem que a abertura comercial e, consequentemente, o comércio exterior foram elementos de grande contribuição para o crescimento econômico desses países. Wacziarg e Welch (2003), em amplo estudo sobre a relação comércio exterior e crescimento econômico, concluem que os países que abriram suas economias ao comércio exterior apresentaram taxas de crescimento econômico 1,5 ponto percentual maiores em relação ao período anterior à exposição ao comércio internacional. Ainda nesse mesmo estudo, os autores mostram que taxas de investimento como o percentual do PIB aumentaram entre 1,5 e 2,0 pontos percentuais no período pós-exposição, ao comércio em relação ao período pré-exposição, e concluem que os países que aumentaram os seus níveis de transação comercial externa aprofundaram as reformas de comércio exterior, aumentando, assim, os ganhos com a exposição externa.

De outra perspectiva, Rodriguez e Rodrik (2000) contestam tal visão, ou seja, que o comércio exterior seja um grande determinante do crescimento econômico. Para tanto, alegam que os estudos são dirigidos a países selecionados, não englobando, portanto, uma teoria ampla e sólida e não especificando as variáveis utilizadas, bem como as relações de causa e efeito. Assim, não é separado o efeito proveniente da abertura comercial daqueles advindos de outros fatores que influenciam o crescimento. No entanto, tais auto- 
res não deixam de concordar que as barreiras comerciais desempenham papel negativo no crescimento econômico. ${ }^{2}$

Jayme Jr. (2001) argumenta que as premissas ${ }^{3}$ adjacentes aos modelos que buscam apontar a relação positiva entre crescimento econômico e comércio exterior são raramente verificadas e propõe outras abordagens a fim de relacionar comércio exterior com crescimento econômico. Chang (2003), com uma visão mais pragmática, compara as políticas comerciais adotadas pelos países em suas estratégias de promoção do crescimento econômico e mostra que as políticas de liberalização comercial vistas como panaceia ao crescimento econômico dos países em desenvolvimento nunca foram adotadas em sua plenitude pelos países desenvolvidos, apesar de indicarem a sua prática aos seus parceiros em desenvolvimento.

Vê-se, portanto, que a simples identificação causal entre crescimento econômico e comércio exterior não é trivial, e qualquer tentativa de explicar essa relação corre o risco de ser facilmente refutada se não for acompanhada de consistente embasamento teórico e empírico.

\section{DADOS UTILIZADOS}

Neste trabalho, como já mostrado, utilizam-se informações sobre contas nacionais com o propósito de explicar se o comércio internacional tem contribuído para o crescimento econômico de alguns países do Leste Asiático. A justificativa para a escolha desse grupo de países está no debate sobre a capacidade do comércio exterior de alavancar o crescimento dessas economias, pois há estudos (Greenaway, Morgan e Wright, 2002; Wacziarg, Welch, 2003) que atestam que essa relação positiva entre crescimento econômico e comércio exterior tem sido altamente significante para os países do Leste Asiático. Entretanto, outros estudos (Rodriguez e Rodrik, 2000) tentam mostrar que essa relação nem sempre é direta, e outros fatores merecem ser estudados, pois a verificação dos efeitos do comércio exterior no crescimento econômico nem sempre é fácil. Há, ainda, a percepção dos autores quanto à carência de estudos nacionais dirigidos a outros países, muito comuns em centros de pesquisa de universidades estrangeiras.

A partir dessas constatações, este trabalho propõe-se, por meio de uma base comparativa estável (mesma fonte de dados), estudar os efeitos do co- 
mércio exterior no crescimento econômico de alguns países do Leste Asiático, considerando algumas técnicas de estimação que amenizam os problemas da correta identificação dos efeitos do comércio no produto desses países, ou seja, evidências empíricas consistentes da relação entre essas variáveis.

Para este propósito, as variáveis utilizadas são o Produto Interno Bruto (PIB), como indicador do crescimento econômico e, variáveis relacionadas com o comércio exterior dos países da amostra, como crescimento das exportações e volume do comércio exterior, tais como mostrado por Krugman e Obstfeld (2004). A seguir as definições de cada variável e que são costumeiramente encontradas nos livros de macroeconomia e contabilidade social:

- PIB: neste trabalho, a variável dependente mostra o valor de todos os bens e serviços finais produzidos em um determinado país em um determinado período de tempo (Dornbush, Fischer e Startz, 2003). A denominação de finais dá-se pelo fato de em cada estágio produtivo ser descontado o valor dos insumos utilizados provenientes da fase anterior, resultando em um valor agregado em cada fase. Neste trabalho, foram utilizadas as taxas de crescimento percentual anuais do PIB de cada país.

- Comércio exterior: foram utilizados dois indicadores de comércio exterior: a taxa de crescimento anual das exportações (cresexport), em termos percentuais, no período considerado, e o indicador de volume de comércio (ln_volcom), representado pelo somatório das importações e exportações. Este último indicador busca captar os efeitos do comércio tanto pelo lado do aumento de exportações, que, por sua vez, elevam o PIB, já que os produtos utilizados utilizam os fatores domésticos na sua produção, quanto pelo lado das importações, que captam acréscimos de renda no país doméstico que possibilitam aumentar o volume das importações, justificativa essa que se encontra no cerne da teoria ricardiana das vantagens comparativas anteriormente explicadas. A variável volume de comércio aqui utilizada refere-se ao somatório em dólares das exportações e importações nas rubricas fob e cif, respectivamente. ${ }^{4}$

- Poupança (poup): a inclusão dessa variável é por demais controversa. Por um lado, há a tradição da economia neoclássica que assume uma identidade entre renda e consumo; se não houver o consumo de toda a renda disponível, ela será investida (Dornbush, Fischer e Startz, 2003), aumentan- 
do, assim, o PIB. Todavia, segundo a lógica keynesiana, de cunho mais heterodoxo (pós-keynesianos), a identidade entre poupança e investimento não é tão simplória, e outros fatores, como a preferência pela liquidez, eficiência marginal do capital e taxas de juro influenciam na decisão de alocar a renda não consumida para o investimento (Paulani e Braga, 2001). Dessa maneira, foi utilizado o indicador de poupança bruta doméstica como percentual do PIB a fim de captar a contribuição da poupança no crescimento do PIB.

- Câmbio (cambio): as taxas de câmbio entre os países foi mensurada pela média anual do valor da moeda doméstica em relação ao dólar. A inclusão dessa variável justifica-se pela importância da política cambial nos padrões de comércio entre os países e, indiretamente, pela sua influência no crescimento do PIB. Tais implicações da política cambial na determinação do comércio entre os países e sua influência no PIB são objetivamente discutidas por Krugman e Obstfeld (2004) e por Dornbush, Fischer e Startz (2003), que mostram os efeitos de políticas cambiais que buscam incrementar o comércio exterior, como, por exemplo, uma desvalorização cambial que pode trazer consequências adversas, como choques inflacionários e dificuldade nas importações de insumos produtivos, cujos resultados podem ser, dentre outras coisas, sérias limitações na capacidade de crescimento do país que as pratica, ou seja, um efeito inverso ao esperado. Todavia, em certas ocasiões a desvalorização é o único caminho, dadas as condições existentes. ${ }^{5}$

- Inflação (infla): a taxa de inflação de um país representa a velocidade de crescimento dos preços. Neste texto, os preços considerados para o modelo foram os preços ao consumidor. A importância da inclusão dessa variável reside na sua influência na determinação das políticas econômicas que acarretam mudanças na determinação do PIB. Assim, quando há altas taxas de inflação, um dos instrumentos de política monetária que os governos utilizam na contenção dos preços é o aumento das taxas de juros, que, por sua vez, influencia nas decisões de investimento (Dornbush, Fischer e Startz, 2003).

- Formação bruta de capital fixo (FBKF): esse indicador agrega os bens que não são utilizados durante um único ciclo de consumo, ou seja, diferentemente dos estoques, eles não "desaparecem" com uma única utilização, mas contribuem para outros ciclos produtivos (Paulani e Braga, 2001). Des- 
sa maneira, espera-se que altas taxas de FBKF estejam relacionadas com altas taxas de investimento, e, por decorrência do modelo keynesiano básico de determinação da renda, presente nos livros-texto, estejam relacionadas com o crescimento do PIB.

- Investimento direto externo (FDI ou PIB): o PIB compreende os fluxos internacionais de capital pelos quais uma empresa em um país cria ou expande uma filial em outro (Krugman e Obstfeld, 2004). Essa expansão abrange não somente os investimentos do tipo greenfield, ou seja, construção de novas fábricas, mas também a compra do controle acionário. Com isso, esse fluxo de capital relacionado ao IDE permite que haja não somente contribuição com as taxas de investimento da economia que as recebe, mas também os efeitos de transferência de tecnologia, que contribuem para o desenvolvimento do conhecimento no país receptor e efeitos de transbordamento para outras indústrias. ${ }^{6}$ Neste trabalho, o IDE foi mensurado em milhões de dólares líquidos, ou seja, o IDE recebido menos o IDE enviado ao exterior pelo país considerado.

- Reservas (reservas): esse indicador permite que se observe o efeito das restrições externas no crescimento econômico, ${ }^{7}$ pois, uma vez que o crescimento econômico aumenta a demanda por bens e serviços externos, sejam eles para consumo (decorrente do aumento da renda) ou para investimento (aumento da capacidade produtiva), as restrições de capitais externos podem gerar necessidades de contração econômica em virtude do estrangulamento do setor externo (Krugman e Obstfeld, 2004). A mensuração desta variável deu-se pela média anual do somatório das moedas estrangeiras e ouro convertidos em dólar pelo câmbio médio do período.

- Investimentos governamentais (gastocap): a inclusão dessa variável justifica-se pelo seu papel nas taxas de investimento e, por conseguinte, no crescimento econômico. Dornbush, Fischer e Startz (2003) analisam de forma bem simples o papel dos investimentos na taxa de crescimento econômico segundo a teoria do crescimento de cunho neoclássico, e Jayme Jr. (2001) apresenta a importância do investimento governamental segundo uma ótica pós-keynesiana. Ambos os trabalhos concordam com o papel importante do investimento (público e privado) na determinação da renda. Neste trabalho, foi mensurado o investimento governamental como o per- 
centual do gasto de capital do governo em relação à arrecadação total. Tal fato permite que não sejam necessárias conversões cambiais entre as moedas dos países com relação a uma mesma moeda-base.

- Educação (educa): o papel da educação no crescimento econômico encontra forte apelo nas novas teorias do crescimento econômico, uma vez que tais modelos destacam a importância do aprendizado e seus efeitos sobre a apropriação tecnológica (Barro, 1998). Dornbush, Fischer e Startz (2003) mostram, por meio de comparações entre países, uma forte relação positiva entre crescimento econômico e anos de escolaridade. Todavia, como não havia informações completas e uniformes dos anos de escolaridade dos países estudados, foi utilizado percentual dos gastos com educação em relação aos gastos totais com uma proxy para a variável escolaridade.

- Crescimento da força de trabalho (labor_change): a quantidade de força de trabalho é uma variável presente tanto nos textos que tratam do crescimento econômico (Dornbush, Fischer e Startz, 2003), nos quais as funções de produção são derivadas a partir de variáveis como capital e trabalho, como nos textos de comércio exterior (Krugman e Obstfeld, 2004) que tratam da mobilidade de fatores, entre eles o trabalho, na determinação das funções de oferta de bens dos países e implicações para a determinação do nível de comércio internacional e preço desse fator entre os países. ${ }^{8}$ A partir dessas constatações, utilizou-se a variação anual da força de trabalho para controlar os efeitos desse fator de produção.

Todas as variáveis utilizadas foram extraídas do banco de dados do Asian Development Bank, ${ }^{9}$ em sua publicação anual Key Indicators, o que permite uma base comparativa relativamente consistente, uma vez que as metodologias de cálculos das variáveis seguem procedimentos semelhantes e permitem comparações menos viesadas. Assim, os dados possuem periodicidade anual e mesma forma de metodologia de construção, permitindo base comparativa mais estável entre os países da amostra.

\section{A ANÁLISE EM PAINEL}

Um conjunto de dados em painel é aquele que segue uma determinada amostra de indivíduos ao longo do tempo, fornecendo múltiplas informações sobre cada indivíduo na amostra. Assim, em cada momento do tempo 
( $t$ ) têm-se várias informações sobre cada componente da amostra ( $n$ ).Com isso, há ganhos quanto à maior variabilidade da amostra, menor colinearidade entre as variáveis, mais graus de liberdade na estimação e nos testes de hipótese (Wooldridge, 2003).

Ainda, uma das motivações que levam ao uso da metodologia de painel nos estudos aplicados de países, como é o caso aqui, está no fato de o painel permitir um controle pela heterogeneidade individual não observada, ou seja, características individuais de cada elemento (n) da observação, como, por exemplo, o ambiente institucional de um país (governo, sistemas de inovação), suas políticas discricionárias para setores específicos (por exemplo, políticas industriais de incentivo às exportações ou de substituição de importações) ou outras características idiossincráticas que são de difícil mensuração ou foram omitidas na amostra.

Para melhor elucidação do modelo em painel, suponha uma amostra de observações de características de $N$ indivíduos ao longo de $T$ períodos, denotados por $Y_{i t}$ e $X_{i t}, \operatorname{com} i=1, . ., N$ e $t=1, \ldots, T$. Assim, a equação de interesse seria:

$$
Y_{i t}=\beta_{0}+\beta_{1} X_{i t}+u_{i t}
$$

onde se tem uma observação de cada indivíduo em cada momento do tempo. No entanto, em se tratando de características específicas não observáveis, o modelo torna-se:

$$
Y_{i t}=X_{i t} \beta+c_{i}+u_{i t}
$$

onde $c_{i}$ é uma característica individual de cada elemento da amostra que é invariante no tempo (note-se que nesta variável há somente o subscrito $i$, e não o $t$ ). Tal característica pode ser, como já se comentou, peculiaridades institucionais de cada país e, no caso de estudo de firmas, capacidades gerenciais diferentes de cada uma delas.

A ideia aqui, então, é obter a $\mathrm{E}\left(y \mid x_{1} \ldots x_{k}, c_{i}\right)$, com uma amostra de tamanho $k$. Sob as suposições de exogeneidade estrita, ou seja:

$$
E\left(u_{t} \mid X_{1}, X_{2}, \ldots, X_{t}\right)=0, \forall t
$$


E com a suposição de satisfação das condições de ortogonalidade: $E\left(X_{i t} C_{i}\right)$ $=0$, o estimador $(B)$ dos parâmetros de interesse $\beta$ é dado por:

$$
\beta=\left(X^{\prime} X\right) X^{\prime} y
$$

Ou seja, o estimador idêntico ao de mínimos quadrados ordinários. No entanto, como aponta Wooldridge (2002), essas suposições quase nunca são encontradas em dados reais. Assim, uma das maneiras de obter estimativas consistentes quando não encontrada as condições de ortogonalidade seria a eliminação da característica idiossincrática não observável pela subtração de (3) na seguinte equação:

$$
\bar{y}_{i}=\bar{x}_{i} \beta+c_{i}+\bar{u}_{i}
$$

De maneira que resultaria a seguinte equação:

$$
\left(y_{i t}-\bar{y}_{i}\right)=\left(x_{i t}-\bar{x}_{i}\right) \beta+\left(u_{i t}-\bar{u}_{i}\right)
$$

Fazendo $\ddot{y}=\left(y_{i t}-\bar{y}_{i}\right), X^{\prime}=\left(x_{i t}-\bar{x}_{i}\right)^{\prime}$ e $U=\left(u_{i t}-\bar{u}\right)$, a estimativa $(B) \operatorname{de} \beta$ é consistentemente obtida por:

$$
\beta=\left(X^{\prime} X\right) X^{\prime} \ddot{y}
$$

que é o mesmo estimador por OLS, todavia, aplicado à variável subtraída por sua média intragrupo, daí sua denominação por estimador within (ou intragrupo), ou de efeitos fixos (EF). Contudo, se as condições de exogeneidade não forem atendidas, outras formas de estimação são utilizadas. ${ }^{10}$

Sob a suposição de ortogonalidade, um estimador comumente usado é o de efeitos aleatórios (EA), que pode ser escrito da seguinte maneira:

$$
y_{i t}=\beta_{0}+\beta_{1} x_{1, i t}+\ldots+\beta_{k} x_{K, i t}+v_{i t}
$$

onde $v_{i t}=c_{i}+u_{i t}$ é um termo de distúrbio composto do efeito não observável e da parte não sistemática do modelo, geralmente chamado de erro composto.

Nota-se, portanto, que o estimador de EA permite que a característica individual não observável esteja correlacionada com as variáveis explanatórias e "coloca" as características individuais não observáveis no erro composto $v_{i t}$. Assim, pode-se dizer que as suposições do modelo de EA são mais 
fortes que as utilizadas pela metodologia de EF. Por exemplo, não se pode afirmar que a característica individual de uma firma, como a capacidade gerencial, não está relacionada com o setor de atividade e o acúmulo de conhecimento ao longo do tempo pela interação com outras firmas, bem como não se pode afirmar que o ambiente regulatório-institucional de um país não possui relação com o nível de educação de sua população e com as taxas de crescimento econômico, que por muitas vezes podem forçar mudanças de caráter institucional.

\section{ESTIMAÇÃO E RESULTADOS}

A estimação do modelo foi feita de modo a identificar quais variáveis influenciaram o crescimento do PIB dos países asiáticos considerados no período 1995-2005. Assim, para cada variável considerada poderia ser considerado um bloco de 88 observações, já que são oito países em oito anos. Contudo, por se tratar de um painel em que nem todas as variáveis possuem valores observáveis para todos os anos e para todos os indivíduos (painel balanceado), não se pode dizer que há essas 88 observações para cada variável.

Entretanto, as variáveis de interesse neste trabalho (PIB, crescimento das exportações e volume do comércio) possuem valores para todos os anos, ou seja, somente há observações faltantes para o restante das variáveis de controle.

O método econométrico utilizado foi a técnica de painel descrita na seção anterior, tendo sido feitas estimativas comparativas entre EF e EA a fim de averiguar a melhor adequação do modelo.

Antes de mostrar a forma funcional do modelo e seus resultados, seguem algumas estatísticas descritivas dos dados utilizados (tabela 1).

Nota-se pela análise da tabela acima que o crescimento econômico dos países analisados situa-se acima dos $4 \%$ a.a., com especial destaque para Índia e China, com crescimento bem mais acelerado que os outros países. Vale lembrar ainda que os resultados mostrados compreendem o período da crise asiática na segunda metade da década de 1990 do século passado, que por si só não mostrou efeitos significativos prolongados no desempenho econômico desses países.

Nos gráficos 1 e 2 evidenciam-se de maneira mais clara os efeitos da crise no crescimento econômico desses países, e seus reflexos nos índices de comércio exterior: 
Tabela 1: Média dos indicadores utilizados: período 1995-2005

\begin{tabular}{|c|c|c|c|c|}
\hline & Coreia & Filipinas & s Malásia In & ndonésia \\
\hline Crescimento do PIB (\%) & 4,98 & 4,13 & 5,30 & 3,36 \\
\hline Crescimento das exportações (\%) & 11,11 & 11,33 & 12,41 & 7,72 \\
\hline Volume de comércio (milhões de US\$) & 331.412 & 69.475 & 620.278 & 953.59 \\
\hline Reservas internacionais (milhões de US\$) & 99.867 & 13.921 & 36.306 & 27.169 \\
\hline Poupança doméstica interna (\% do PIB) & 34,55 & 16,86 & 43,75 & 27,52 \\
\hline $\begin{array}{l}\text { Variação da taxa de câmbio em relação ao dólar } \\
\text { (\% de variação anual) }\end{array}$ & 3,42 & 7,49 & 3,97 & 25,43 \\
\hline Taxa de inflação (\% preço ao consumidor) & 3,75 & 5,98 & 2,59 & 14,16 \\
\hline FBKF (\% do PIB) & 31,49 & 0,43 & 29,00 & 23,90 \\
\hline $\begin{array}{l}\text { Investimento do governo (\% de gasto com capital } \\
\text { em relação ao gasto total) }\end{array}$ & 18,15 & 6,63 & 32,28 & 30,77 \\
\hline Despesas com educação (\% das despesas do governo) & 17,64 & 16,99 & 22,90 & 6,19 \\
\hline Investimento direto externo (milhões de US\$) & 1.086 & 1.128 & 3.067 & 699 \\
\hline & Taiwan & China $\mathrm{H}$ & Hong Kong & Índia \\
\hline Crescimento do PIB (\%) & 4,70 & 9,26 & 3,36 & 6,55 \\
\hline Crescimento das exportações (\%) & 9,75 & 18,86 & 6,44 & 17,12 \\
\hline Volume de comércio (milhões de US\$) & 8.409 & 601.150 & 3.279 .645 & 5.046 \\
\hline Reservas internacionais (milhões de US\$) & 145.771 & 288.579 & $99.536 \epsilon$ & 6.0479 \\
\hline Poupança doméstica interna (\% do PIB) & 25,72 & 40,64 & 30,69 & 26,13 \\
\hline $\begin{array}{l}\text { Variação da taxa de câmbio em relação } \\
\text { ao dólar (\% de variação anual) }\end{array}$ & 1,96 & $-0,45$ & 0,06 & 3,26 \\
\hline Taxa de inflação (\% preço ao consumidor) & 1,27 & 2,85 & 0,87 & 5,97 \\
\hline FBKF (\% do PIB) & 3,96 & 39,19 & 26,66 & 26,63 \\
\hline $\begin{array}{l}\text { Investimento do governo (\% de gasto com capital } \\
\text { em relação ao gasto total) }\end{array}$ & 26,85 & 19,46 & 21,60 & 25,48 \\
\hline Despesas com educação (\% das despesas do governo) & 10,62 & 8,17 & 19,83 & 13,19 \\
\hline Investimento direto externo (milhões de US\$) & -2.997 & 43.772 & 1.189 & 3.050 \\
\hline
\end{tabular}

Fonte: ADB (2008)

Observa-se pelos gráficos citados que os efeitos da crise asiática, sucedida pela crise russa, foram mais pronunciados no início deste século, com forte redução do produto e queda das exportações, grande fator de expansão dessas economias. Contudo, vê-se também que somente três economias (China, Índia e Taiwan) não chegaram a ponto de apresentar crescimento econômico negativo, e somente as duas maiores economias analisadas, a chinesa e, indiana, não apresentaram taxas de crescimento de exportações negativas. Além disso, pelos gráficos adiante também é possível observar que a queda nas exportações foi verificada em período posterior à queda do PIB em cerca de quatro anos. Tal fato pode ser atribuído ao efeito imediato da crise asiática sobre a economia desses países e a efeitos posteriores agra- 
Gráfico 1: Taxa do crescimento do PIB (\%)

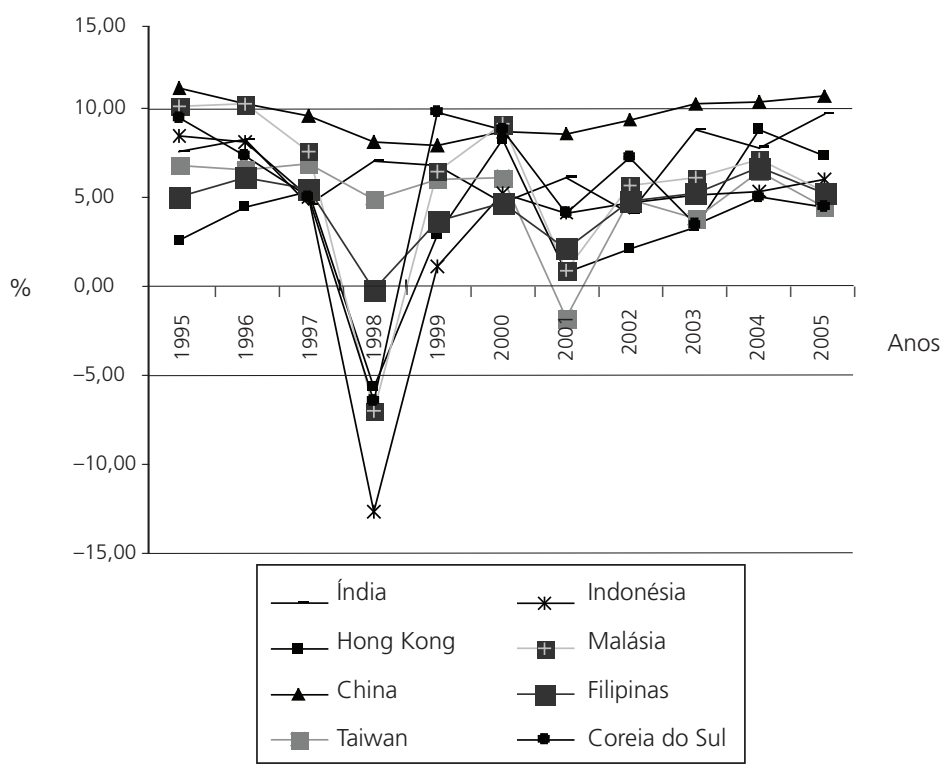

Fonte: Elaborado pelos autores a partir dos dados de ADB (2008).

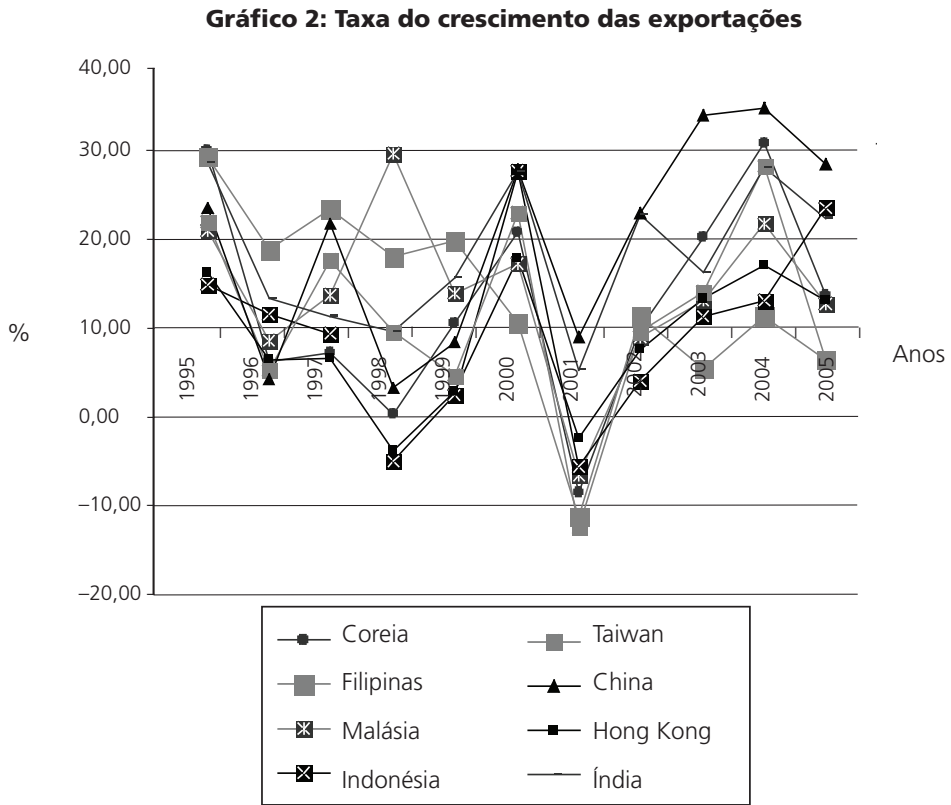

Fonte: Elaborado pelos autores a partir dos dados de ADB (2008). 
vantes, como a crise da Rússia e a bolha especulativa das empresas "ponto. com" no início do século XXI, que propagou forte efeito pelas economias no mundo com retração de investimentos externos, elemento esse de grande importância para as economias aqui analisadas.

A seguir, são mostrados os resultados da estimação do modelo por EA e EF por meio da utilização do software Stata $10 .{ }^{11}$

Nos resultados das estimativas mostrados nas tabelas, em que a variável dependente é o crescimento anual do PIB em termos percentuais, tem-se que a variável crescexport, que denota o crescimento anual percentual das exportações dos países analisados, é significativa a 5\% tanto considerando a estimativa por efeitos aleatórios quanto por efeitos fixos. Ou seja, assumindo ou não que as características não observáveis específicas de cada país estão correlacionadas com as variáveis explanatórias (independentes), a taxa de crescimento das exportações possui influência significativa no crescimento do PIB. O mesmo não se pode dizer de outra variável indicativa de comércio exterior ln_volcom, que apresentou significância estatística próxima a $10 \%$ somente na estimativa por efeitos aleatórios.

Para averiguar se os modelos estimados são adequados sob as suposições do método de efeitos aleatórios comentados anteriormente, foi realizado o teste de Hausman nos modelos estimados. Esse teste tem como hipótese nula a consistência dos estimadores de EA, ou seja, a rejeição da hipótese nula implica consistência dos estimadores de EF e inconsistência dos estimadores de EA (Baum, 2006). O teste apresenta uma distribuição qui-quadrado $\left(x^{2}\right)$ e não rejeitou a hipótese nula, sendo encontrado um valor da Prob $>x^{2}=0,92$, ou $x^{2}$ encontrado de 3,19 . Isso reafirma a capacidade da variável relacionada ao crescimento das exportações na explicação do crescimento econômico, pois esta apresentou-se significativa nos dois métodos de estimação (EF e EA), ou seja, é relevante ao modelos mesmo sob suposições mais restritivas.

Quanto ao restante das variáveis, os resultados são muito divergentes dependendo do método utilizado. Por exemplo, por efeitos aleatórios, a variável poupança interna (poup) é significativa a $1 \%$; já por efeitos fixos não apresenta significância estatística. Uma variável que apresentou significância nos dois métodos de estimação foi a relacionada ao crescimento da força de trabalho, confirmando, assim, as hipóteses subjacentes aos modelos de crescimento econômico presentes nos livros-texto de macroeconomia. 
Tabela 2: Resultados da estimação por efeitos aleatórios

\begin{tabular}{lcccc}
\hline & Coeficiente & Erro-padrão & $t$ & $P r>t$ \\
\hline cambio & $-0,081$ & 0,019 & $-4,27$ & 0,000 \\
\hline reservas & $(*)$ & $(*)$ & $(*)$ & $(*)$ \\
\hline cresexport & 0,086 & 0,031 & 2,77 & 0,006 \\
\hline poup & 0,124 & 0,056 & 2,20 & 0,028 \\
\hline fdi & $(*)$ & $(*)$ & $(*)$ & $(*)$ \\
\hline educa & $-0,061$ & 0,062 & $-0,98$ & 0,328 \\
\hline infla & 0,007 & 0,078 & 0,09 & 0,927 \\
\hline In_volcom & $-0,388$ & 0,241 & $-1,61$ & 0,107 \\
\hline gastocap & $-0,052$ & 0,035 & $-1,45$ & 0,146 \\
\hline labor_change & 0,450 & 0,212 & 2,13 & 0,033 \\
\hline$\alpha$ & 6,53 & 2,56 & 2,55 & 0,011 \\
\hline Prob > F & 0,000 & 0,64 & &
\end{tabular}

(*) Valores com baixa significância econômica e estatística dos coeficientes. A variável dependente (crescimento do PIB) e as independentes são aquelas descritas no texto. Total de observações: 532 países $x$ ano.

Tabela 3: Resultados da estimação por efeitos fixos

\begin{tabular}{lcccc}
\hline & Coeficiente & Erro-padrão & $t$ & $\operatorname{Pr}>t$ \\
\hline cambio & $-0,074$ & 0,022 & $-3,28$ & 0,002 \\
\hline reservas & $(*)$ & $(*)$ & $(*)$ & $(*)$ \\
\hline cresexport & 0,084 & 0,032 & 2,59 & 0,012 \\
\hline poup & 0,113 & 0,155 & 0,73 & 0,468 \\
\hline fdi & $(*)$ & $(*)$ & $(*)$ & 0,511 \\
\hline educa & 0,067 & 0,101 & $-0,32$ & 0,747 \\
\hline infla & $-0,0349$ & 0,107 & 0,53 & 0,600 \\
\hline In_volcom & 1,126 & 2,138 & $-1,42$ & 0,160 \\
\hline gastocap & $-0,637$ & 0,044 & 2,44 & 0,018 \\
\hline labor_change & 0,555 & 0,227 & $-0,48$ & 0,633 \\
\hline Constante & $-12,57$ & 26,17 & & \\
\hline Prob $>$ F $=$ & 0,000 & & & \\
R2 $=$ & 0,32 & & & 0 \\
\hline
\end{tabular}

(*) Valores com baixa significância econômica e estatística dos coeficientes. A variável dependente (crescimento do PIB) e as independentes são aquelas descritas no texto. Total de observações: 532 países $x$ ano.

Por fim, algumas variáveis apresentaram significância econômica (edu$\mathrm{ca}$, infla, gastocap), pois seus coeficientes estimados mostraram valores diferentes de zero, mas baixa significância estatística, e outras apresentaram baixa significância econômica e estatística (como é o caso das variáveis relacionadas ao investimento externo direto e ao volume de reservas). Contudo, não se pode afirmar que as variáveis mencionadas anteriormente sejam de pouca relevância para o crescimento econômico de um país. Tal afirmação 
depende da verificação de potenciais problemas de endogeneidade do modelo e, métodos de estimação mais complexos (como estimação por painel dinâmico) não abordados aqui se tornam necessários.

Para tentar amenizar esses problemas, foram adotados alguns procedimentos. Em primeiro lugar, foi utilizado o método de variáveis instrumentais ${ }^{12}$ para analisar se a variável volume de comércio (ln_volcom) é um bom instrumento para "crescexport", e, se o for com significância estatística, pode-se concluir que ambas são significativas para o modelo e possuem influência na taxa de crescimento do PIB. Além disso, a variável cambio foi defasada de um período na estimação, pois os efeitos de oscilações na taxa de câmbio, apesar de ocorrerem com certa defasagem, são geralmente observados muito antes das outras variáveis aqui analisadas.

Ainda, considerando que as características idiossincráticas de cada país estão correlacionadas com as variáveis explanatórias, ou seja, o ambiente regulatório-institucional influencia a determinação das variáveis aqui analisadas, como lembrado por Chang (2003), foram utilizadas estimativas por efeitos fixos e por primeiras diferenças (FD). Na estimativa por FD, ao invés de subtrair-se a equação (7) na equação (4) para obter a equação (8), subtrai-se então a variável defasada de um período, obtendo-se assim:

$$
\Delta \mathrm{Y}_{i, t}=\Delta \mathrm{X}_{i, t} \beta+\Delta \mathrm{u}_{i, t}
$$

em que: $\quad \Delta Y_{i t}=Y_{i, t}-Y_{i, t-1}$

$$
\begin{aligned}
& \Delta X_{i, t}=X_{i, t}-X_{i, t-1} \\
& \Delta u_{i, t}=u_{i, t}-u_{i, t-1}
\end{aligned}
$$

E tem-se agora que $t=2,3, \ldots T$, já que uma observação é utilizada na transformação para primeira diferença. Nota-se, também, que as características não observáveis, $c_{i}$, também são eliminadas na diferenciação, já que esta é constante ao longo do tempo para cada indivíduo da amostra.

Nas tabelas 4 e 5 são mostrados os resultados da estimação com essas técnicas.

O primeiro resultado que merece destaque é quanto a significância estatística (5\%) da variável crescimento das exportações, instrumentalizada pela variável volume de comércio (In_volcom), em ambas as metodologias. Contudo, devido à eliminação de observações na estimativa por FD, a hipó- 
tese de sobreidentificação (estatística de Sargan) na utilização de variáveis instrumentais somente foi rejeitada na estimativa por efeitos fixos. Observase, também, que o sinal dessa variável é o esperado pela literatura (Wacziarg e Welch, 2003). Além disso, nota-se também que os valores referentes ao ajuste do modelo (R2) também aumentaram significativamente em relação às estimativas das tabelas 2 e 3 , mantendo a significância do modelo.

Tabela 4: Resultados da estimação por efeitos fixos e variáveis instrumentais

\begin{tabular}{lcccc}
\hline & Coeficiente & Erro-padrão & $t$ & $P r>t$ \\
\hline cambio (D1) & 0,003 & 0,0124 & 0,27 & 0,784 \\
\hline reservas & $(*)$ & $(*)$ & $(*)$ & $(*)$ \\
\hline cresexport (instrum.) & 0,076 & 0,034 & 2,24 & 0,025 \\
\hline poup & 0,057 & 0,133 & 0,43 & 0,669 \\
\hline fdi & $(*)$ & $(*)$ & $(*)$ & $(*)$ \\
\hline educa & 0,031 & 0,121 & 0,26 & 0,797 \\
\hline infla & $-0,342$ & 0,056 & $-6,07$ & 0,000 \\
\hline gastocap & $-0,070$ & 0,055 & $-1,27$ & 0,203 \\
\hline labor_change & 0,748 & 0,217 & 3,43 & 0,001 \\
\hline Constante & 4,396 & 7,09 & 0,62 & 0,536 \\
\hline Prob>F $=0,0000$ & & & & \\
\hline R2 & & &
\end{tabular}

R2 $=0,463$

Sargan $x^{2}(1) P-$ val $=0,2716$

(*) Valores com baixa significância econômica e estatística dos coeficientes. A variável dependente (crescimento do PIB) e as independentes são aquelas descritas no texto. A variável cambio foi defasada em um período e a variável cresexport foi instrumentalizada pela variável In_volcom. Total de observações: 532 países $x$ ano.

Tabela 5: Resultados da estimação em primeira diferença e variáveis instrumentais

\begin{tabular}{lcccc}
\hline & Coeficiente & Erro-padrão & $t$ & $\operatorname{Pr}>t$ \\
\hline cambio (D1) & 0,008 & 0,015 & 0,53 & 0,598 \\
\hline reservas & $(*)$ & $(*)$ & $(*)$ & 0,923 \\
\hline cresexport (instrum.) & 0,077 & 0,034 & 2,27 & 0,023 \\
\hline poup & $-0,105$ & 0,265 & $-0,40$ & 0,691 \\
\hline fdi & $(*)$ & $(*)$ & $(*)$ & $(*)$ \\
\hline educa & $-0,033$ & 0,179 & $-0,19$ & 0,850 \\
\hline infla & $-0,383$ & 0,063 & $-6,05$ & 0,000 \\
\hline gastocap & $-0,120$ & 0,0781 & $-1,55$ & 0,122 \\
\hline labor_change & 0,665 & 0,227 & 2,92 & 0,004 \\
\hline constante & $-0,193$ & 0,523 & $-0,37$ & 0,711
\end{tabular}

Prob $>\mathrm{F}=0.0000$

$\mathrm{R} 2=0.46$

Sargan $\chi^{2}(1) P-$ val $=0.0046$

(*) Valores com baixa significância econômica e estatística dos coeficientes. A variável dependente (crescimento do PIB) e as independentes são aquelas descritas no texto. A variável cambio foi defasada em um período e a variável cresexport foi instrumentalizada pela variável In_volcom. Total de observações: 532 países $x$ ano. 
Outra variável que merece observação é a inflação, pois nas estimativas anteriores (tabelas 2 e 3) não havia apresentado significância estatística, mas mostrou-se significativa em ambas as técnicas mostradas nas tabelas 4 e 5 e com sinal negativo, tal como apresentado pela teoria de trade-off entre crescimento e inflação, representada pela curva de Phillips modificada (Dornbush, Fischer e Startz, 2003).

Dessa maneira, observa-se que os resultados fundamentais permanecem inalterados, ou seja, o papel significativo do comércio exterior no crescimento econômico dos países estudados, mesmo variando as técnicas de estimação dos modelos, de acordo com resultados teóricos anteriores (Krueger, 1990; Wacziarg e Welch, 2003).

\section{CONCLUSÃO}

Neste trabalho foi mostrado que estabelecer uma ligação entre abertura ao comércio exterior de um país e seu crescimento econômico ainda é fonte de muitos questionamentos e debates entre os pesquisadores de economia internacional.

A fim de contribuir com esse debate, o trabalho propôs-se estudar a contribuição do comércio exterior para o crescimento econômico de algumas economias asiáticas por meio da metodologia de painel, que fornece resultados em que são expurgados as características individuais dos países. Além disso, técnicas de estimação por variáveis instrumentais foram utilizadas para amenizar os problemas de endogeneidade.

Os resultados apontam que, mesmo com a utilização de técnicas diferentes, o comércio exterior desempenhou papel significativo e positivo no crescimento dos países asiáticos aqui estudados para o período 1995-2005, em favor das teorias de abertura comercial e orientação exportadora. Ainda, os resultados apontam que as utilizações de técnicas que buscam minimizar os problemas de endogenia corroboram o ajuste dos modelos.

Assim, esses resultados adicionam uma contribuição empírica baseada em fundamentos teóricos presentes na literatura acerca dos efeitos do comércio exterior no crescimento econômico, não ficando, assim, restritos às contestações retóricas e de convicção sem qualquer embasamento fundamentado e verificável, às vezes observada nas discussões político-econômi- 
cas sobre o papel da inserção externa (cujo comércio é um dos principais meios) no produto do país.

Contudo, os resultados aqui apresentados estão longe de ser indicativos incondicionais de aceitação ou refutação de uma ou outra teoria. Apenas levantam a questão sobre a necessidade de estudos que busquem uma melhor argumentação sobre a relação comércio exterior e crescimento econômico, inclusive com a utilização de técnicas de estimação mais avançadas, como a metodologia em painel dinâmico. Mas, a utilização dessas técnicas são dependentes de um horizonte de disponibilidade de dados que nem sempre estão disponíveis em bases comparáveis, tal qual utilizado neste trabalho.

\section{NOTAS}

1. Grande parte da teoria do comércio exterior apoia-se no argumento das vantagens comparativas. Para um melhor detalhamento desse tema, ver Krugman e Obstfeld (2004).

2. "...there is a strong negative relationship in the data between trade barriers and economic growth" (Rodriguez e Rodrik, 2001, p. 19).

3. A premissa maior é a hipótese de Hecksher-Ohlin-Samuelson de equalização dos fatores. Para um tratamento prático dessa hipótese, ver Krugman e Obstfeld (2004).

4. A sigla FOB (free on board) representa o valor de embarque da mercadoria, e a sigla CIF (cost, insurance and freight) inclui, além do custo propriamente dito das mercadorias, os fretes e seguros relacionados ao seu transporte.

5. Veja-se, por exemplo, a situação da Argentina no início do século XXI, na qual a desvalorização foi uma saída única para a situação econômica do país, ou mesmo o caso do Brasil no início de 1999.

6. O vencedor do Prêmio Nobel de Economia de 2008, Paul Krugman, foi agraciado com a honraria em virtude de suas diversas pesquisas sobre a alocação de produção em diferentes países e seus efeitos nas economias receptoras.

7. Para uma discussão mais profunda sobre a relação da restrição na balança de pagamentos e o crescimento econômico, ver Thirlwall (1997).

8. Krugman e Obstfeld (2004) fazem um breve detalhamento das teorias de mobilidade da força de trabalho e implicações para o preço de equilíbrio desse fator.

9. Para mais detalhes em relação ao banco de dados, ver: <www.adb.org $>$.

10. Para uma melhor explanação das formas de estimação em painel, suas suposições e tratamento quando do relaxamento delas, ver Wooldridge (2002).

11. A estimação foi feita utilizando o comando xtreg do software, comando esse utilizado para dados em painel. A base de dados e as rotinas estão à disposição mediante a solicitação aos autores.

12. Para uma explicação objetiva sobre a motivação e o método das variáveis instrumentais, ver Wooldridge (2002). 


\section{REFERÊNCIAS BIBLIOGRÁFICAS}

ASIAN DEVELOPMENT BANK (ADB). Key indicators. $<$ http://www.adb.org $>2008$.

BARRO, R. J. Notes on growth accounting. NBER Working Paper, Cambridge, MA: National Bureau of Economic Research, n. 6.654, 1998.

BAUM, C.F. Introduction to Modern Econometrics Using Stata. 1. ed. Texas: Stata Press. 2006.

BYRGE, J.A.; PAKKO, M.R. Freedom, Trade and Growth. International Economic Trends, Federal Reserve Board of Saint-Louis, 2006.

CHANG, H-J. Chutando a escada - a estratégia de desenvolvimento em perspectiva histórica. São Paulo: Unesp, 2003.

DORNBUSH, R.; FISCHER, S.; STARTZ, R. Macroeconomia. 8. ed. Rio de Janeiro: McGraw-Hill Interamericana do Brasil, 2003.

FRANKEL, J. A.; ROMER, D.; CYRUS, T. Trade and growth in east asian countries: cause and effect? NBER Working Paper, Cambridge, MA: National Bureau of Economic Research, n. 5.732, 1996.

FUKUDA, S; TOYA, H. Conditional Convergence in East Asian Countries: The Role of Exports for Economic Growth. Discussion Paper, Tokyo: Economic Research Institute, Economic Planning Agency, n. 57, 1993.

GREENAWAY, D.; MORGAN, W.; WRIGHT, P. Trade Liberalization and Growth in Developing Countries. Journal of Development Economics, v. 67, n. 1, p. 229-244, 2002.

JAYME JR., F. G. Notes on trade and growth. Texto para Discussão, Cedeplar-UFMG, Belo Horizonte, n. 166, 2001.

KRAAY, A. Exports and Economic Performance: Evidence from a Panel of Chinese Enterprises. Washington, D. C.: World Bank Press, 1997.

KRUEGER, A. O. Asian Trade and Growth Lessons. American Economic Review, v. 80, n. 2, p. 108-112, 1990.

KRUEGER, A. O. Trade Policy and Economic Development: How We Learn. American Economic Review, v. 87, n. 1, p. 1-22, 1997.

KRUGMAN, P. R.; OBSTFELD, M. Economia Internacional: teoria e politica. 5. ed. São Paulo: Pearson Education do Brasil, 2004.

LEE, H. Y.; RICCI, L. A.; RIGOBON, R. Once Again, Is Openess good for Growth? NBER Working Paper, Cambridge, MA: National Bureau of Economic Research, n. 10.749, 2004.

PAULANI, L.M.; BRAGA, M. B. A nova contabilidade social. 1. ed. São Paulo: Saraiva, 2001.

RODRIGUEZ, F.; RODRIK, D. Trade Policy and Economic Growth: A Skeptic's Guide to the Cross-National Evidence. NBER Macroeconomic Annual 2000, Cambridge, MA, 2000.

THIRLWALL, A. Reflections on the concept of balance-of-payments-constrained growth. Journal of Post Keynesian Economics, v. 19, n. 3, p. 377-385, 1997.

VENTURA, J. A Global View of Economic Growth. NBER Working Paper, Cambridge, MA: National Bureau of Economic Research, n. 11.296, 2005. 
WACZIARG, R.; WELCH, K. H. Trade Liberalization and Growth: New Evidence. NBER Working Paper, Cambridge, MA: National Bureau of Economic Research, n. 10.152, 2003.

WOOLDRIDGE, J. M. Econometrics Analysis of Cross Section and Panel Data. 1. ed. Cambridge, MA: MIT Press, 2002.

WOOLDRIDGE, J. M. Introductory Econometrics. 2. ed. Cincinnati, Ohio: South-Western College Publishing, 2003. 